\title{
CONCEPÇÕES SOBRE GÊNERO E FORMAÇÃO NO CAMPO DA PSICOLOGIA DA SAÚDE
}

\author{
CONCEPCIONES SOBRE GÉNERO Y FORMACIÓN EN EL CAMPO DE LA \\ PSICOLOGÍA DE SALUD
}

\author{
GENDER CONCEPTIONS AND PROFESSIONAL TRAINING IN THE FIELD OF \\ HEALTH PSYCHOLOGY
}

\author{
Florêncio Mariano da COSTA-JÚNIOR ${ }^{1}$ \\ Bettina dos Santos ALMEIDA ${ }^{2}$ \\ Rinaldo CORRER ${ }^{3}$
}

RESUMO: A reflexão sobre o gênero na atuação profissional e no ensino dos cursos de graduação contribuem significativamente para pensar novas formas de instrumentalizar práticas. Modelos de masculinidades e feminilidades mantêm e são mantidos por discursos sexistas em diferentes cenários, incluindo o contexto da saúde. A noção de uma predisposição feminina a distúrbios físicos e emocionais, baseada em padrões sociais de fragilidade, culminou na criação de especialidades em saúde que visam a prevenir o adoecimento. $\mathrm{O}$ masculino, permeado por noções de resistência e força, se tornou sinônimo de corpo saudável, ratificando a dominação masculina e o papel político e econômico dos homens, influenciando o distanciamento dos homens nos cuidados com saúde. Este estudo investigou as concepções de 05 psicólogas atuantes no contexto hospitalar e ambulatorial sobre relações de gênero e saúde, por meio de entrevistas semiestruturadas e análise de conteúdo. Os dados ratificam outros achados de pesquisas no campo da saúde ao indicar o processo de generificação de práticas em saúde e seus possíveis desdobramentos no atendimento prestado. Os resultados obtidos poderão contribuir para a discussão da assistência psicológica prestada e as relações de gênero, bem como contribuir para uma formação que aborde as questões de gênero de forma interdisciplinar.

PALAVRAS-CHAVE: Gênero. Saúde. Ensino. Psicologia.

RESUMEN: La reflexión sobre género en la actuación profesional y en la enseñanza de las carreras de grado contribuye significativamente para pensar nuevas formas de instrumentalizar prácticas. Modelos de masculinidades y femineidades se mantienen por discursos sexistas en distintos escenarios, incluyendo el contexto de la salud. La noción de una

${ }^{1}$ Universidade Estadual Paulista (UNESP). Araraquara - SP - Brasil. Docente do Programa de Pós-graduação em Educação Sexual. Professor na Faculdades Integradas de Bauru. ORICD: <http://orcid.org/0000-0003-4155589X>. E-mail: mcostajunior@gmail.com

${ }^{2}$ Universidade Estadual Paulista (UNESP). Bauru - SP - Brasil. Discente no Programa de Pós-graduação em Psicologia do Desenvolvimento e Aprendizagem. ORICD: 〈http://orcid.org/0000-0001-8624-0336>. E-mail: bettina.salmeida@gmail.com

${ }^{3}$ Universidade Estadual Paulista (UNESP). Araraquara - SP - Brasil. Docente do Programa de Pós-graduação em Educação Sexual. Professor na Faculdades Integradas de Bauru. ORICD: <http://orcid.org/0000-0002-83141647>. E-mail: correr.rinaldo@gmail.com

RIAEE - Revista Ibero-Americana de Estudos em Educação, Araraquara, v. 14, n. esp. 2, p. 1441-1464, jul., 2019. E-ISSN: 1982-5587. 
predisposición femenina a disturbios físicos y emocionales, basada en patrones sociales de fragilidad, culminó en la creación de especialidades en salud que visan a prevenir enfermedades. El masculino, permeado por nociones de resistencia y fuerza, se volvió sinónimo de cuerpo saludable, ratificando la denominación masculina y el papel político y económico de los hombres, influenciando el alejamiento de los hombres en los ciudadanos con salud. Este estudio investigó las concepciones de 05 psicólogas actuantes en el contexto hospitalario y ambulatorio sobre relaciones de género y salud, por medio de entrevistas semiestructuradas y análisis de contenido. Los datos ratifican otros hallazgos de investigaciones en el campo de la salud al señalar el proceso de generificación de prácticas en salud y sus posibles desdoblamientos en la atención prestada. Los resultados obtenidos podrán contribuir para la discusión de la asistencia psicológica prestada y las relaciones de género, así como contribuir para una formación que aborde las cuestiones de género de forma interdisciplinaria.

PALABRAS CLAVE: Género. Salud. Enseñanza. Psicología.

ABSTRACT: The Reflection about gender in both professional performance and teaching of the graduate courses significantly contributes to thinking new ways of instrumentalizing practices. Masculinity and femininity models keep and are kept by sexist speeches in different settings, including the health context. The notion of a female predisposition to physical and emotional disorders, based on social patterns of frailty, culminated in the creation of health specialties aimed at preventing such illness. The male, permeated by notions of resistance and strength, has become a synonymous of healthy body, reaffirming the male dominance and the political and economic role of men, influencing their distancing from the cares with health. This study investigated the concepts of 05 active psychologists in hospital and outpatient contexts about gender and health relations through semi-structured interviews and content analysis. The data confirm other research findings in the health field by indicating the gendering process of the health practices and its possible effects in the care provided. The results may contribute to the discussion of the psychological care provided and the gender relations and contribute to a training addressing gender issues in an interdisciplinary way.

KEYWORDS: Gender. Health. Health psychologists. Teaching of psychology.

\section{Introdução}

Ao longo da história, as diferenças entre homens e mulheres despertaram interesses da ciência e da sociedade. Durante décadas o discurso do senso comum, muitas vezes respaldado pela ciência, salientou a diferença entre os gêneros, reforçando a dominação masculina e colocando as mulheres em um patamar intelectual, psicológico e físico inferior aos homens (KRIEGER; FEE, 1994; ROHDEN, 2003). A noção de gênero e as configurações sobre o masculino e o feminino não determinam somente as atitudes e os comportamentos interpessoais a serem adotados, a partir daqueles esperados socialmente, mas também influenciam a forma como os indivíduos devem perceber e lidar com seus corpos (CONNELL, 1995; DOYAL, 
2001; KORIN, 2001). Segundo Rohden (2002), a mulher é tratada no discurso biomédico como eminentemente exclusiva à função sexual/reprodutiva e, com base nessa visão biológica, foram definidos papéis sociais - suas características anatômicas e fisiológicas as destinavam à maternidade e aos contextos domésticos e privados. Diferentemente do homem, a mulher se afetaria mais com as mudanças da puberdade, gravidez e menopausa, pois estaria governada por sua fisiologia (ROHDEN, 2002; 2003). No século XIX, a ideia de que o desenvolvimento de uma sociedade saudável dependeria do monitoramento corporal e psicológico das mulheres construiu as bases para as ciências médicas, incluindo a ginecologia moderna: a medicina da mulher (ROHDEN, 2003). A noção de que as mulheres eram mais sensíveis às doenças e psicologicamente instáveis estabeleceu a necessidade de uma especialidade para garantir que a fragilidade inata feminina e sua vulnerabilidade não acarretassem danos à reprodução. No decorrer da história, as sociedades impuseram critérios rígidos de comportamento para as compreensões e o manejo sobre o corpo feminino. Nesse âmbito, as características que não correspondessem ao que estava prescrito levaram muitas mulheres a serem marginalizadas diante da sociedade devido a suas práticas sexuais ou ideológicas (ROHDEN, 2002; 2003). Toda essa conjuntura produziu marginalização e discriminação social, e a busca de condutas adaptativas diante de tais prescrições se torna uma exigência para as mulheres, sendo tal discurso ainda reproduzido no ensino de ciências da saúde que reproduzem concepções antiquadas acerca do gênero.

Caracterizado como padrão de saúde, o masculino permaneceu fora do olhar das ciências da saúde, o que talvez tenha contribuído para que a exposição corporal e o cuidado com sua saúde sejam mais difícil para os homens. Culturalmente o corpo masculino ainda é visto como um corpo designado ao trabalho e à promoção do desenvolvimento social. A ideia de corpo forte, viril e resistente permeia a concepção de masculino na sociedade atual (GOMES; NASCIMENTO; ARAÚJO, 2007). Ao passo que o campo da saúde atribuía ao feminino diferentes tipos de vulnerabilidade, ao masculino a noção de resistência e estabilidade ainda vigora (GOMES, 2003; KORIN, 2001; ROHDEN, 2003). Os estudos contemporâneos afirmam que o gênero é um fator altamente influente na caracterização dos padrões de morbimortalidade. Na construção de gênero, muitos homens assumem riscos que interferem em suas condições de saúde e as mulheres, por vezes, aceitam constrangimentos impostos sobre o seu corpo (GOMES; NASCIMENTO; ARAÚJO, 2007; COSTA-JUNIOR, COUTO; MAIA, 2016; FERRAZ; KRAICZYK, 2017). Além disso, há uma disposição maior de serviços e de programas de saúde voltados ao público feminino, tanto para atendimento médico quanto para 
a realização de exames preventivos. Os homens, de modo geral, recorrem a farmácias ou prontos-socorros (BRAZ, 2005) e relatam não se sentirem acolhidos nos serviços de saúde disponíveis (GOMES; NASCIMENTO; ARAÚJO, 2007). Segundo Fagundes et al. (2009), cabe à psicologia enquanto compromisso social com a categoria, a sociedade e os direitos humanos, não permitir que esse campo de estudo e prática seja utilizado para sustentar as relações de desigualdade fundamentadas no sexo. Deverá, de modo contrário, promover discursos alternativos que questionem o discurso dominante opressivo, identificando e desconstruindo estruturas sociais e práticas pessoais e profissionais que sustentam o sexismo e funcionam como instrumentos de controle social.

A Psicologia da saúde envolve a consideração do contexto social e cultural no qual a saúde e a doença ocorrem, tendo em conta que a saúde depende não só dos comportamentos e estilo de vida individual, mas também de influências sociais e comunitárias, condições de vida e de trabalho, influências culturais e ambientais. Teixeira e Correia (2002) aconselham que no tocante às influências do gênero, o objetivo principal da investigação em Psicologia no campo da saúde deve ser o de identificar quais são os mediadores psicológicos da influência do gênero na saúde. Ainda que a Psicologia tenha sido um campo de produção dos estudos sobre gênero e sexualidade, os estudos de Nuernberg (2005) e Machado, Barreto e Grossi (2014) discutem o quanto são restritos os contextos de ensino em Psicologia que consideram as questões de gênero na formação em Psicologia. As pesquisas no campo da saúde devem se fundamentar nos diferentes conceitos de saúde e doença e nas diferentes formas de proteger a saúde, dando visibilidade a variadas formas de lidar com o processo saúde-adoecimento. Considerando tal papel, a educação em saúde deve considerar o gênero como um constructo fundante para conhecer as particularidades de homens e mulheres e assim propor suas intervenções. A produção científica relacionada ao ensino da categoria gênero na formação em Psicologia, a partir de estudos empíricos, ainda é escassa, principalmente investigando esse tema entre os profissionais de psicologia da saúde que têm contato direto com mulheres e homens no atendimento preventivo e terapêutico. Nesse sentido, estudar o que relatam tais profissionais sobre como homens e mulheres se engajam nos cuidados com a saúde, bem como o atendimento que lhes são prestados, nos parece uma questão fundamental que poderia produzir conhecimentos mais abrangentes sobre o tema e contribuir para futuras propostas curriculares que incluam o gênero e a sexualidade nos cursos de formação em Psicologia. 


\section{Método}

Este estudo se classifica como uma investigação de natureza qualitativa e descritivo (GOMES, 2008; MINAYO, 2006). Participaram do estudo 05 psicólogas que atuam em serviços de atenção à saúde em um município do interior paulista. Todas as participantes cursaram a graduação em Universidades particulares, trabalham na área da saúde há mais de 2 anos, e estavam em contato direto e cotidiano com o atendimento de homens e mulheres, diante de questões de diagnóstico, tratamento e acompanhamento de saúde/doença. O delineamento da pesquisa considerou a participação de psicólogos no sentido de diversificar a amostra de participantes em relação ao sexo e ao gênero, no entanto não foi possível viabilizar a participação de um Psicólogo, pois nos hospitais do município não havia homens que atuassem na área.

A seguir está apresentado o Quadro 1, que caracteriza as participantes da pesquisa.

Quadro 1 - Apresentação das Participantes da Pesquisa

\begin{tabular}{|c|c|c|c|c|c|}
\hline \multirow{2}{*}{$*$} & \multirow{2}{*}{$\begin{array}{l}\text { Idade } \\
\text { (anos) }\end{array}$} & \multirow{2}{*}{$\begin{array}{c}\text { Atuação } \\
\text { (anos) }\end{array}$} & \multirow{2}{*}{$\begin{array}{c}\text { Atuação Profissional } \\
\text { (área) }\end{array}$} & \multicolumn{2}{|c|}{ Natureza do serviço que trabalha } \\
\hline & & & & (local) & (setor) \\
\hline P1 & 28 & 3 & Hospitalar & Ambulatório de Especialidades & Público \\
\hline $\mathrm{P} 2$ & 28 & 3 & Neuropsicologia/Hospitalar & Serviço de Atenção hospitalar & Público \\
\hline P3 & 27 & 2 & Hospitalar & Serviço de Atenção hospitalar & Público \\
\hline P4 & 31 & 3 & Hospitalar & Serviço de Atenção hospitalar & Privado \\
\hline P5 & 32 & 5 & Hospitalar & Serviço de Atenção hospitalar & Privado \\
\hline
\end{tabular}

Fonte: Elaboração própria.

* Participantes do estudo codificados para garantir o anonimato

Para a produção dos dados empíricos foi utilizado um roteiro de entrevista semiestruturada, previamente elaborado pelos autores e testado em situação piloto. O roteiro de entrevista foi organizado em três blocos temáticos. O Bloco 1- "Concepções do masculino e feminino" investigou como as profissionais compreendem questões de Gênero, ou seja, noções sociais sobre o masculino e o feminino. O Bloco 2- "Gênero e Comportamentos de cuidados com a saúde" buscou identificar as ideias, teorias ou hipóteses que as depoentes têm sobre a influência do gênero em relação à prevenção, aos cuidados com a saúde e com o tratamento da doença. Por fim, o Bloco 3 - "Formação e prática profissional na área da saúde e questões de gênero" teve a finalidade de coletar informações sobre a prática profissional relacionada com as demandas masculinas e femininas de seus clientes/pacientes. Nesse bloco, a prática profissional e a formação acadêmica foram destacadas visando conhecer se as concepções dos 
participantes poderiam basear-se em discussões sobre Gênero obtidas em seus respectivos cursos de formação.

A seleção das participantes se deu por meio de amostra por conveniência utilizando a técnica de "bola-de-neve" (FERNANDES; CARVALHO, 2000). Para a realização das entrevistas, as profissionais foram contatadas, informadas dos objetivos da pesquisa e convidadas para a participação no estudo. As entrevistas foram agendadas e realizadas em local e horário convenientes às participantes, garantindo privacidade e ambiente adequado para a entrevista. Todos os procedimentos éticos em pesquisa com seres humanos foram atendidos e o projeto da pesquisa recebeu parecer favorável do Conselho de Ética em Pesquisa local (parecer 075/12). Todas as entrevistas foram realizadas nas dependências do próprio serviço de saúde. Tais entrevistas foram gravadas e transcritas na íntegra e analisadas tal como propõe Bardin (1979).

\section{Resultados e discussão}

A análise dos dados possibilitou que as concepções, ideias e pontos de vista das participantes fossem agrupados em categorias de análise correspondentes e os dados analisados serão apresentados a seguir. As categorias que emergiram nos relatos estão apresentadas a seguir e elucidadas com citações de trechos dos relatos das participantes.

\section{Gênero como uma diferenciação entre os atributos da feminilidade e masculinidade}

As entrevistadas P1, P2, P4 e a P5 relataram o gênero como algo que vai além da sexualidade, mas que é um produto dos atributos de masculinidade e feminilidade:

Para mim não é necessariamente relacionado à sexualidade. É o ser, é a feminilidade e a masculinidade, termos de jeito de ser, de gosto, de afinidade $(P 1)$.

Sexo esta mais relacionado ao biológico e gênero muito mais com relação à concepção do sujeito sobre si e sua própria identidade se masculino ou feminino $(P 2)$.

Já P3 remete a noção de gênero como vinculado ao campo da diferença sexual e da sexualidade. 
É, eu entendo? Boa pergunta, [risos], bom deixa eu pensar né? É, [silêncio, suspiro], o que eu entendo de gênero? É, pera ae, [risos], a diferenciação de sexualidade, então, é, acho que seria isso, diferenciação de sexualidade.

Retomando o conceito definido por Scott (1988), no qual gênero é a organização social para a diferença sexual. Gênero é a categorização de pessoas, artefatos, eventos, sequências e tudo o que desenha o corpo e as dimensões sociais baseadas nos atributos dele (KOFES,1992). Nesse sentido, mesmo se tratando de profissionais da Psicologia, os relatos ainda trazem um viés reducionista sobre o gênero, uma vez que o relacionam ao campo dos atributos de gênero e à sexualidade, deixando de lado as demais dimensões relacionais e de poder do gênero. No entanto, as concepções acerca do que é gênero apresentam uma maior amplitude e complexidade quando comparamos com os entrevistados do estudo de Costa-Júnior (2010), que entrevistou médicos/as e enfermeiras/os. Para as profissionais da Psicologia entrevistadas, o gênero não se delimitaria ao sexo biológico e isto parece ser um grande diferencial que pode capacitar mais este ramo da ciência para pensar, discutir e atender as demandas relativas à construção social do gênero e seu impacto sobre a saúde psicológica.

A concepção atrelada ao gênero remonta à interpretação dos atributos de feminilidades e masculinidades como conjunto de características de mulheres ou homens. Neste aspecto se torna necessário desnaturalizar os elementos que socialmente definem o feminino e o masculino. Para Afonso (2007), no nível sociológico, masculino e feminino, masculinidade e feminilidade não são apenas dados da natureza, mas sim um trabalho da cultura sobre esses dados. Portanto são entidades reais, simbólicas e imaginárias que coadunam na formação das subjetividades dos indivíduos que habitam e são socializados em um dado contexto cultural. Os atributos tidos como tipicamente masculinos e tipicamente femininos, os quais podemos denominar respectivamente de atributos de masculinidades ou feminilidades, fazem parte da construção social do gênero e das relações de poder envolvidas e são papéis ou condutas, esperadas socialmente de acordo com o sexo biológico. Podem, portanto, restringir a ampla gama de possibilidades as quais os indivíduos potencialmente possuem. As diferenças sexuais variam nas diferentes culturas e poderiam ser chamadas de papéis de gênero e é interessante pensar como tais diferenças constroem as supostas diferenças psíquicas (CECCARELLI, 1999).

Segundo Ceccarelli (1999), o sentimento que se traduz por "eu sou masculino" ou "eu sou feminina", que se refere à masculinidade e à feminilidade, é resultado de investimentos e identificações, num corpo suporte de representações, marcando assim suas funções e seus desejos. Ainda para este autor, masculinidade e feminilidade são adquiridas e isto 
independentemente do sexo anatômico. Desta forma não é por ser anatomicamente do sexo feminino que a criança se posicionará necessariamente como menina, se identificando "naturalmente" com as prerrogativas femininas (CECCARELLI, 1999).

\section{Características e atributos comportamentais segundo o sexo}

Nesta categoria agrupamos as concepções que abordam o feminino e a feminilidade e o masculino e a masculinidade como conjunto de estereótipos que definem a mulher e o homem em termos de papéis sociais e atributos. As participantes definiram a delicadeza, a sensibilidade, a maternidade, a capacidade de fazer várias atividades ao mesmo tempo, a atenção e ao cuidado de si e do próximo, como atributos próprios da mulher. Como podemos ver nos relatos:

O feminino é aquele que consegue fazer várias coisas ao mesmo tempo, é que tem uma graciosidade nisso tudo, além disso, a concepção de feminino tem muito a ver com a maternagem, com o cuidar, o cuidado. (P2)

O que eu posso falar de feminino é mais sensibilidade, uma pessoa assim que a gente vê muito mais emoção. (P5)

Para Rohden (2001), as características femininas refletiriam a missão passiva que a natureza reservada da mulher, além de uma predisposição à maternidade. No século XIX, a mulher passa a adquirir maior importância médico-social, sobretudo em função dos problemas ligados à maternidade, ao aleitamento, à masturbação (ROHDEN, 2001).

O masculino é visto como papéis que dizem respeito aos homens e como objetividade, força e rigidez. Como é possível analisar nos relatos:

A masculinidade não é uma coisa ríspida, mas não tão delicado quanto ao feminino. Seria mais um instinto provedor, do que ofeminino. (P1)

O masculino, do ponto de vista cultural, eu acho que ele caracteriza força, pilar. O masculino ele um pouco é mais objetivo, um pouco mais focal em algumas coisas, talvez um pouco mais racional. (P2)

O homem tem um pouco mais de workaholic do que é aquela coisa do trabalho e tal, relacionado ao masculino, que diz ter que sustentar a família. (P2)

Então seria o masculino e a masculinidade um conjunto de estereótipos que definem o homem. Muitos autores descrevem que historicamente o corpo masculino foi concebido no campo da ciência e do senso comum como superior ao feminino (ROHDEN, 2001) e, segundo Connell (1995), a masculinidade pode ser compreendida como uma configuração de prática em torno da posição dos homens na estrutura das relações de gênero. Ainda para este autor, a 
dominação masculina e a subordinação feminina constituem o principal eixo de poder na ordem de gênero nas sociedades ocidentais. Socialmente o homem é visto como autoridade no lar, autônomo e livre frente a outros homens, é forte e corajoso, não podendo expressar emoções, é o provedor do lar, e é heterossexual. Ainda que no campo das relações concretas o homem não apresente tais atributos, há um modelo hegemônico de masculinidade tido como parâmetro e atua como nivelador daquilo que se define como masculino e masculinidade. Mesmo que sua realidade não seja esta, o homem que ocupa posições subalternas e subordinadas de masculinidade se esforça ao máximo para alcançar e ratificar a masculinidade hegemônica, reproduzindo tais padrões nas suas interações com a sociedade (FIGUEIREDO, 2008; CONNELL, 1995).

Para Lamas (2007), as diferenças anatômicas são uma simbolização cultural que se formam em um conjunto de práticas, ideias, discursos e representações culturais que influenciam e determinam o comportamento. Ainda para Lamas (2007), homens e mulheres são iguais como seres humanos, e existem apenas duas áreas onde há uma diferenciação, o da sexualidade e o da procriação, e para ele o corpo é a única evidência incontestável da diferença entre o homem e a mulher.

\section{Contextos produtores e reprodutores dos atributos de masculinidades e feminilidades}

Esta categoria se refere aos contextos sociais que do ponto de vista das entrevistadas constroem formas e expressões do que é ser homem ou mulher. Quando questionadas acerca dos fatores que produziriam estes diferentes atributos, as participantes apontaram a cultura como um fator decisivo para a aprendizagem e manutenção destes. A condição cultural se refere à maneira que o feminino é visto culturalmente, como sensibilidade, fragilidade e beleza.

Está muito implicado à uma condição cultural, eu poderia dizer que o feminino caracteriza a sensibilidade, fragilidade, beleza, mas sinceramente, pessoalmente, não acho que tem nada disso em feminino, eu atribuiria características como multifacetado. (P2)

Além das questões biológicas de órgão, de órgãos sexuais, é, acho que representa todo papel social que é do feminino, ah, é a questão que a gente aprende, os papéis [...] A questão que a gente aprende desde as coisas que a menina gosta, desde os papeis dentro da família. (P3)

Para elas os atributos são construídos socialmente, desde a criança até o adulto, tanto homem como mulher. Como condição cultural, temos os fatores socioculturais que promovem 
a aprendizagem de ser homem e ser mulher. Segundo Negreiros e Feres-Carneiros (2004), não existe um conteúdo universal para os papéis do gênero, já que são construções históricas, sociais e culturais. Nos dias atuais, é importante, tanto para o homem quanto para a mulher, manter seu status, para que a sua identidade seja provada socialmente.

Dentro desta categoria, encontramos as características sociais do masculino e do feminino. Costa-Junior (2010) destaca a percepção de profissionais da saúde sobre a repressão social que impõe normas comportamentais em função do gênero. Bandura (1971), Biaggio (1976) e Kohlberg (1966) estudaram aspectos variados quanto à aprendizagem de papéis masculino e feminino, e para eles as diferenças psicossociais entre meninos e meninas são de certo modo apreendidas desde tenra idade. Agentes socializadores influenciam, por meio de diferentes interações, as disposições, atitudes e comportamentos típicos para cada sexo, ensinando uma noção do que é ser homem ou ser mulher, e do que é esperado, permitido, consentido e excluído para tal.

Os relatos trazem concepções de atributos de gênero como produto das histórias de socialização e isto nos parece um avanço na forma como se compreende o que é gênero e seus constituintes culturais, quando comparado às concepções naturalizantes de outros profissionais da saúde, tal como aponta a pesquisa de Costa-Junior (2010).

\section{Diferenças de homens e mulheres nos cuidados com a saúde}

Para Colom e Zaro (2007) é possível entender a heterogeneidade dos comportamentos dos homens e mulheres perante a saúde e a enfermidade, incorporando-se nela os fatores psicológicos, culturais, sociais e econômicos. A partir dos relatos foi possível captar as concepções relacionadas às especificidades que existem nas formas de cuidado e os possíveis condicionantes que produzem formas de cuidado distintas segundo o gênero. Os resultados apresentam que, para todas as participantes, as mulheres cuidam mais da saúde, procuram mais especialistas buscando a prevenção, enquanto que os homens só procuram profissionais da saúde quando a doença já se manifestou. Como relata a entrevistada P1 respondendo quem cuida mais da saúde:

elas tomam mais cuidado, que elas vão mais ao médico, principalmente em termos de prevenção. O homem é mais quando o problema já está instalado e eles correm atrás do prejuízo. (P1) 
Estes dados corroboram com pesquisas anteriores que investigaram as concepções de profissionais da saúde sobre a influência do gênero nos cuidados de si. Costa-Junior e Maia (2009) e Figueiredo e Schraiber (2008) relatam que o cuidado com a saúde não é valorizado como uma questão importante no contexto masculino e indicam que para as profissionais da Psicologia da saúde as diferenças de cuidados também são notadas em suas atividades profissionais. Caracterizado como padrão de saúde, o corpo masculino permanece fora do olhar das ciências da saúde, o que talvez tenha contribuído para que a exposição do próprio corpo e o cuidado com sua saúde seja mais difícil para os homens. Culturalmente o corpo masculino ainda é visto como um corpo designado ao trabalho e à promoção do desenvolvimento social. A ideia de corpo forte, viril e resistente, permeia a concepção de masculino na sociedade atual e resulta na pouca presença dos homens nos serviços de atenção primária (COSTA-JUNIOR; MAIA, 2009; GOMES; NASCIMENTO; ARAÚJO, 2007). Autores como Macintyre, Ford e Hunt (1999) e Verbrugge (1989) sugerem que homens são menos propensos a reportar problemas de saúde ao seu grupo de apoio e aos profissionais da saúde enquanto há uma grande procura feminina aos serviços de saúde. No campo da saúde, atribuía-se ao feminino uma predisposição a distúrbios orgânicos e psicológicos e, ao mesmo tempo, ao masculino, a noção de resistência e de responsabilidade sobre a manutenção social e econômica (GOMES, 2003; KORIN, 2001; ROHDEN, 2003).

\section{Prevenção e adoecimento segundo o sexo}

Segundo as entrevistadas as mulheres adoecem menos e se previnem mais. Nos relatos existe a percepção de que as mulheres se preocupariam mais com a doença. Podemos citar os relatos:

(...) A gente vê que as mulheres se preocupam bastante, muito mais que os homens, geralmente quando eles vêm é porque é uma situação que não aguentam. (P5)

A questão da diferença do adoecimento físico e psicológico em relação ao gênero emerge nos relatos, destacando a ideia de que o adoecimento psicológico é maior entre as mulheres, e os homens teriam, por sua vez, mais adoecimento físico.

As mulheres adoecem mais de repente psicologicamente. O homem exatamente por ele ter essa dificuldade de repente de olhar pra si e de cuidar de si, eu vejo que ele tem mais predisposição de repente pra desenvolver patologias mais físicas. (P3) 
Tal concepção possivelmente se dá pelo fato de a mulher ter um espaço social resguardado para suas queixas subjetivas, fragilidade emocional e outras demandas psicológicas. Este adoecimento psicológico pode ser resultado de como o gênero e a educação sexista produz diferentes manifestações se tratando de homem ou mulher, uma vez que é socialmente esperado e reconhecida a queixa subjetiva das mulheres. Miranda e Lobato (2011) relatam que na última década foi possível verificar um aumento nas pesquisas que indicam a multiplicidade de papéis desempenhados pela mulher na sociedade e como isso pode afetar diretamente sua saúde de modo geral, entretanto historicamente foi construída a noção de vulnerabilidade associada ao corpo da mulher, lhes ensinando a serem mais receptiva às terapêuticas biomédicas - sujeitos moralmente responsáveis pelo cuidado de si, sendo-lhes esperada a manifestação de queixas relativas à vulnerabilidades e ao sofrimento.

Rohden (2001) aponta que não há referências sobre a andrologia, a disciplina que se teria constituído para tratar da sexualidade e reprodução do homem.

A ginecologia é toda a produção em torno da sexualidade e reprodução na mulher e se constituiu como um conhecimento elaborado com base na percepção de como as mulheres são diferentes dos homens (ROHDEN, 2001 p. 38).

Rohden (2001) afirma que o andamento da vida feminina, nas suas várias fases, desde a puberdade até a menopausa, é percebido como propício a perturbações e desordens, exigindo um cuidado constante; a ginecologia se constitui sobre essa lógica. Nessa direção se destaca a reflexão de uma das participantes quando a mesma questiona se as mulheres se cuidam mais ou se cuidam mais porque adoecem mais:

Isto é bastante relativo. Nós ganhamos uma grande população de mulheres, é em busca de serviços de saúde, em busca de prevenção de saúde, de cuidados preventivos [...]. mas aí eu pergunto, será que porque as mulheres procuram mais a saúde numa questão preventiva é porque elas de cuidam mais ou porque elas somatizam e realmente adoecem mais? As mulheres geralmente, embora a gente entenda o feminino como aquela que seja mais frágil, elas têm muito mais mecanismos adaptativos de enfrentamento a internação, a doença do que o homem. Não sei se as mulheres se cuidam mais ou se adoecem mais. (P2)

O relato da participante parece representar questionamentos relevantes para a compreensão do gênero como um determinante na forma como os indivíduos cuidam da saúde. Tal concepção sobretudo nos alerta que, no campo da Psicologia da saúde, as relações de gênero ainda não se fundamentaram como premissas para entender as particularidades dos indivíduos 
a partir de uma visão histórica e cultural. A queixa relatada pode não ser sinônimo de adoecimento, e sim de um espaço social para falar sobre questões subjetivas e privadas, e a maior visibilidade do adoecimento feminino está na relação com a invisibilidade do adoecimento masculino e a menor atenção em saúde prestada ao homem. Portanto tais manifestações de vulnerabilidade e adoecimento parecem não se encerrarem no sujeito como ser isolado, no qual ocorrem maior ou menor manifestação de doença ou cuidado, e sim em um contexto social e histórico mais amplo e multideterminado.

A mulher está mais voltada para a questão do cuidado, a gente aprende, culturalmente falando, que nós cuidamos, nós cuidamos da casa, nós cuidamos da família, do marido, dos filhos, acho que a mulher é mais precavida com relação a isso. (P3)

Atualmente sabemos que as mulheres consomem mais medicamentos que os homens, pois são influenciadas e orientadas a tal comportamento no intuito de uma prevenção secundária. Vieira (2002) contextualiza a medicalização do corpo feminino relacionando com a análise feita por Foucault (1982) de que a natureza política da medicina na sociedade capitalista é uma estratégia de controle social que começa com o controle do corpo. Segundo Colom e Zaro (2007), os especialistas reconhecem que as mulheres enfrentam uma situação particular de estresse, que, muitas vezes, explica por que razão utilizam mais os serviços de saúde com relação aos homens. De acordo com Miranda e Lobato (2011), muitos dos sofrimentos vividos pela mulher se configuram pela realização de uma necessidade, na diversidade de papéis que deve desempenhar: quando saudável busca a satisfação de tais necessidades, porém a insatisfação a faz adoecer. Segundo as mesmas autoras, mulheres envolvidas em multiplicidade de papéis sociais são frequentemente confrontadas com vários fenômenos estressores, oportunizando manifestações como diminuição do autoconceito, do autocontrole e da autoestima. De acordo com Martin e Angelo (1996), culturalmente ainda existe uma divisão de papéis entre os pais, cabendo à mulher a responsabilidade de educar, socializar e cuidar dos filhos, e ao homem, o sustento da família.

Além disto, as mulheres têm mais espaços para manifestar suas queixas do que os homens. Estes estudos parecem apresentar uma noção ainda parcial sobre os multideterminantes das condições de adoecimento da mulher e sobremaneira ainda não apresentam uma leitura relacional respaldada na premissa de que homens e mulheres são vulneráveis de acordo com as dimensões sociais e biológicas que lhes afetam diferencialmente. 


\section{Homens e mulheres apresentam repertórios de enfrentamento diferentes quando adoecidos}

Para as participantes, as mulheres apresentam mais repertórios de enfrentamento quando adoecidas, pois, segundo seus relatos, quando internado o homem precisa muito mais de atenção psicológica do que as mulheres. Em contraste aos modelos hegemônicos de masculinidade, os homens, segundo as participantes, são bem mais frágeis que elas. De acordo com Gomes et al., (2007), vários estudos revelam que os homens padecem mais em condições severas e crônicas do que as mulheres. Tal padecimento está relacionado a pouca prevenção primária dos homens, porém não significa que ele realmente precise de mais cuidado quando internado, pois o fato do homem ser socializado a partir das premissas de força e invulnerabilidade, ao ficar doente, não tem repertórios pessoais para reagir a esta nova condição, de ter que ser cuidado, de estar dependente e vulnerável.

A psicologia mesmo é um ponto ai, o homem quando ele vem para o hospital $e$ é acometido de uma patologia, é impressionante como ele desestabiliza, muitos homens desestabilizam. Mulheres têm um mecanismo mais reforçado de enfrentamento. (P2)

Um estudo realizado por Costa-Junior e Maia (2009) indicou que os homens entrevistados afirmaram que as mulheres teriam condições vantajosas para lidar com o tratamento de uma doença, uma vez que, diante da ocorrência do adoecimento, seriam mais otimistas e corajosas e também seriam mais práticas, cuidadosas e responsáveis na adesão ao tratamento. Para eles, as mulheres seriam mais otimistas quanto à cura da doença e teriam melhores condições de aderir ao tratamento médico do que os homens. (COSTA-JUNIOR; MAIA, 2009). De acordo com o estudo de Costa-Junior (2010), do ponto de vista de médicos/as e enfermeiros/as, quando doentes as mulheres têm melhores condições emocionais de aceitar o diagnóstico e aderir ao tratamento, e tal comportamento é aprendido desde a infância. Já os homens têm maior dificuldade em aceitar e aderir ao tratamento devido a uma dificuldade de aceitar a vulnerabilidade do corpo e a dependência em relação a ser cuidado. Para Schraiber $e t$ al. (2005) a participação do homem nas ações de saúde é um desafio, por diferentes razões. Uma delas se refere ao fato de, em geral, o cuidar de si e a valorização do corpo no sentido da saúde, também no que se refere ao cuidar dos outros, não serem questões colocadas na socialização dos homens. Schraiber et al. (2005) destaca que o enfoque de gênero representaria uma contribuição importante no entendimento das barreiras culturais dos homens, ao mesmo 
tempo em que subsidiaria a formulação de programas e melhores campanhas para a saúde masculina.

A adesão do tratamento e dos resultados é algo bem relativo, pois as participantes apontaram que as mulheres aderem mais à intervenção psicológica e que os resultados dependem da adesão e não do gênero, porém, se quem adere mais são as mulheres, os resultados ficam positivos diante disto. Ainda no âmbito do enfrentamento do processo de adoecimento, tanto os homens quanto as mulheres apresentam os mesmos resultados quando aderem ao tratamento, porém, os homens aderem menos ou possuem mais dificuldade para aceitar a intervenção. De acordo com Barbosa (2010), o alcance dos serviços de saúde voltados para as masculinidades deve pautar-se: na compreensão dos homens na qualidade de sujeitos confrontados com as diferentes dimensões da vida, portanto como sujeitos históricos; a organização dos serviços e a forma como estes são direcionados aos seus usuários, respeitandose as delimitações de gênero, para atender os usuários considerando suas subjetividades e por último, os vínculos estabelecidos entre os homens com os serviços e a instituição da qual fazem parte, de acordo com o papel e posição que estão ali representados. Segundo Connell (1995), os modelos de masculinidade mostram como os homens muitas vezes assumem comportamentos considerados pouco saudáveis. Tais comportamentos estão relacionados a um modelo de masculinidade idealizada, a masculinidade hegemônica (CONNELL, 1995). Barbosa (2010), afirma que as noções de invulnerabilidade, de comportamento de risco fazem parte dos valores da cultura masculina. Para as entrevistadas,

Mulheres aderem. Elas têm mais facilidade de falar de si mesma, de suas mazelas. (P2)

As mulheres, muito mais. Mas assim, quando a gente consegue aproximar do homem, do gênero masculino, você vê assim que o conteúdo é muito mais rico. Mas pra você chegar eu acho que eles estão meio que igualados também, porque a hora que ele dispõe você vê que o conteúdo é muito rico também, pra você trabalhar, muitos detalhes. (P5)

Para Aquino (2005), foi preciso retirar a mulher da esfera única da reprodução para dar visibilidade a inúmeras necessidades de saúde, negligenciadas até um certo período pela biomedicina. No Brasil tal mudança gerou a PAISM - Programa de Assistência Integral à Saúde da Mulher. Diante de tais programas a mulher se sente acolhida no campo da saúde e adere mais ao tratamento, diferente dos homens, que até o ano de 2009 não possuíam programas de atenção integral voltados à saúde. Segundo Aquino (2005), atualmente na área de saúde tem-se buscado demonstrar como a "masculinidade hegemônica" gera comportamentos danosos à 
saúde, evidenciando a importância dos homens e da saúde estarem pautados na Saúde Coletiva, e como a feminilidade hegemônica tem contribuído para a medicalização excessiva do corpo da mulher.

\title{
Gênero e interação profissional-paciente
}

Esta categoria apresenta significativo contraste entre concepções sobre o gênero e a interação profissional, ou seja, a atuação profissional no contato com homens ou mulheres. Este contraste se dá pelo fato de que inicialmente as participantes reconhecem a existência de formas distintas para lidar com a saúde e de se vincular com a atenção prestada quando se trata de homens e mulheres, entretanto estas diferenças não são compreendidas quando se trata da intervenção em Psicologia. Os relatos sugerem que no campo da atenção psicológica as relações de gênero são pouco compreendidas como variáveis que diferenciam os sujeitos em suas interações pessoais e na relação com as diferentes instituições. Para as participantes, o fato de ser homem ou mulher não influencia nas atitudes de seus pacientes. Apenas uma entende que a idade pode ser um fator influente, e segundo P2, ao se depararem com uma psicóloga jovem, alguns se assustam e se sentem envergonhados de tocarem em certos assuntos.

\begin{abstract}
O fato de ser mulher ou homem não, eu não vejo como uma influência, eu vejo como uma influência a idade talvez para alguns pacientes. Talvez para conversar sobre algumas condições específicas, então casos bastante específicos, o homem ele tem dificuldade, por exemplo, pacientes que nós atendemos que tem câncer de próstata passaram pelo urologista, então eles têm muita dificuldade para iniciar uma conversação sobre ereção, por exemplo. Quando a gente vai trabalhar na questão mais íntima do sujeito o paciente ele tem um pouco mais de tato, mas de um modo geral, no hospital geral, creio que não. (P2)

Eu vejo aqui como um processo saúdeldoença, às vezes algumas doenças mais graves, alguns procedimentos mais invasivos, então eu costumo pensar mais nessa questão, que tipo de tratamento que ele esta fazendo, ou é uma quimioterapia, ou é uma cirurgia, uma ortopédica, o que isso acarreta, e eu tento trabalhar dessa maneira, acho que não é uma coisa assim, eu tento me direcionar pra ver como eu vou chegar, como que se vai abordar (P5)
\end{abstract}

Além disso, as participantes afirmam não assumir uma postura ou prática diferenciada quando atendem um homem ou uma mulher. Entretanto os relatos apresentam uma contradição quando afirmam que ao se deparar com um homem, e especialmente com queixas relacionadas ao campo da sexualidade e do corpo sexual, a forma de abordar, ou de sugerir a intervenção se modifica, ela age com mais "tato" - cuidado, cautela, precaução. A participante P4 relata que 
quando se trata de um paciente homem, a postura profissional se dá de forma mais reservada e mais cautela para abordar o paciente.

a gente tem que manter a postura, a gente sabe que quando a gente vai conversar com o senhor ou com uma senhora nossa postura tem que ser diferenciada do que com um mais novinho. Acho que pra mim não tem diferença. Mas ao atender um homem eu sou mais reservada. Não que eu tenha tanta diferenciação com uma mulher, mas a gente sempre mantém uma postura mais reservada, porque pode acontecer de ele querer invadir o nosso espaço, sair do foco. (P4)

O meu crivo na verdade é o estilo do paciente, não o gênero, a forma como quando eu abordo a resposta imediata que esse paciente me dá, mas o fato de ser homem não interfere na minha abordagem. (P2)

Segundo P3, conhecendo a resistência masculina, ela teria uma postura de não diferenciar ou considerar as questões de gênero para que isto supostamente não prejudicasse a interação.

Eu não tenho nenhuma dificuldade, pode ser homem ou mulher assim, não, nem por idade, tem algumas coisas, tem o tom de voz, o modo de conversar. Eu acho que a cautela ai é a atitude. E ai se eu perceber que de repente existe isso, eu tento tocar o menos possível nessa questão de gênero, homem, mulher. Eu tento ser o mais empática possível e mostro para ele, assim, que é indiferente de ser homem ou mulher (P3).

Eu acho que não existe essa diferença não de ser homem ou mulher. O que eu acho que dificulta mais, é uma pessoa que não é tão acessível, não é tão aberto, isso dificulta. Mas existe tanto homens quanto mulheres que são desse jeito, então isso não esta ligado ao gênero. Porque até agora os casos que eu atendi não dependeram disso, de ser homem ou se ser mulher (P1).

Parece-nos que a questão da possibilidade de assédio, da diferença sexual entre paciente e profissional e o reconhecimento da profissional em relação a seu sexo, são particularidades que permeiam a diferença na forma com que se trata os/as pacientes em relação ao sexo. E os relatos parecem reproduzir os estereótipos de gênero, uma vez que manifestam concepções sexistas quanto ao homem ser aquele que irá ultrapassar os limites da relação profissional. Nas avaliações de uma das participantes não há uma dificuldade em atender um homem ou uma mulher, e sim em cada caso individualmente, independentemente de ser homem ou mulher. Este relato flexibiliza a questão do gênero ao descrever que outros fatores podem interferir na relação com o paciente e que segundo ela não estariam diretamente relacionados ao gênero. 


\section{Formação em Psicologia e questões de gênero}

A última categoria de análise se refere à discussão e reflexão sobre as relações de gênero na formação em Psicologia. Segundo as participantes, elas não se recordam ou reconheceram existência de estudos específicos durante a graduação sobre as questões de gênero

Não, questão do gênero em si não, nunca parei pra estudar essa questão. (P2)

Não aprofundado, mas a gente estuda isso naquela questão, nas disciplinas de desenvolvimento, da questão de personalidade, eu acho que entra muito também na questão social, porque a gente traz essa questão de cultura muito, de grupo e ai pensando em grupo e sociedade, a gente tem os papéis muito bem distribuídos, eu acho que isso influencia muito na questão da personalidade no modo de ser, então o que eu mais vi de gênero foi nesse tempo assim de graduação referente a essas disciplinas. (P3)

Não me recordo. Eu acho importante. Tem algumas questões como as que você me trouxe hoje que a gente não se depara tanto na nossa rotina, no nosso dia-a-dia, mas ela é muito importante. (P4)

Eu acho que eu tive não uma diferenciação. E acho que seria importante estudar isso (P5).

De acordo com Nuernberg (2005), a categoria gênero foi construída a partir de reflexões originalmente desencadeadas nos movimentos sociais. Segundo Nuernberg (2005), o estudo de gênero na Psicologia iniciou-se no âmbito da Psicologia Social brasileira. O autor destaca que a Psicologia Social contribuía especialmente com os estudos sobre a atribuição, aquisição e desempenho dos papéis sexuais, fazendo algumas vezes o uso de escalas e instrumentos de avaliação destes aspectos psicológicos. Nuernberg (2005), ao analisar os estudos brasileiros na área da Psicologia e do gênero, afirma que se por um lado se colocava a cegueira da Psicologia em relação às questões associadas ao sexo/gênero, por outro, era neste campo do conhecimento (Psicologia Social) que se buscavam argumentos e métodos para algumas pesquisas sobre a mulher. Os conceitos da Psicologia social clássica como estereótipos, atitudes, preconceito, foram a base das primeiras reflexões feministas que dialogavam com a Psicologia, entretanto tais reflexões partiram de um movimento social legítimo e nem sempre vinculado ao contexto universitário. Por isto as reflexões parecem ainda não ter se inserido de maneira consistente nos cursos de formação, de modo a fundamentar um olhar profissional sobre as questões de gênero na saúde e na atenção prestada em Psicologia. Machado et al. (2013) explicam que a Plataforma de Ação de Pequim destacou a importância de integrar o tema gênero nos currículos escolares e propõe que instituições acadêmicas integrem tal temática em suas pesquisas, objetivando o estimulo da igualdade.

RIAEE - Revista Ibero-Americana de Estudos em Educação, Araraquara, v. 14, n. esp. 2, p. 1441-1464, jul., 2019. E-ISSN: $1982-5587$ 
Apesar de o gênero ser discutido na Psicologia Social, ele não está nos currículos de formação em Psicologia de modo geral, dificultando assim a atuação profissional, principalmente na área da saúde, já que os profissionais não são convidados, durante a graduação, a pensar e refletir sobre as questões de gênero e como isto pode influenciar na atividade profissional futura. Machado et al. (2013, p. 68) afirmam que a implementação das discussões de gênero e sexualidade não se dá sem entraves. Na graduação, as barreiras impostas por outros processos sociais são referendadas por um conjunto de dificuldades específicas. É possível dizer que tais discussões podem ser citadas, porém não aprofundadas adequadamente, impedindo a preparação do profissional após a graduação, tendo em vista que ele poderá se deparar com essas questões, e como explicado pelas participantes, terem dificuldade de lidar com essa temática. Book (2003), citado por Machado et al. (2013, p. 69), explica que a abordagem de tais conteúdos depende largamente do envolvimento de cada professor com essa questão, bem como de seu comprometimento social e percepção de sua atuação como lócus (ou não) de transformação social. Com esses dados é possível confirmar que, no tocante às influências do gênero, o objetivo principal da investigação em Psicologia da saúde deve ser o de identificar quais são os mediadores psicológicos da influência do gênero na saúde, já que todas as participantes afirmaram que não estudaram as questões de gênero relacionando-o ao adoecimento ou à saúde psíquica durante a graduação.

\section{Considerações finais}

A partir dos relatos é possível perceber uma relação entre as questões de gênero e o cuidado com a saúde de homens e mulheres, destacando as mulheres quanto ao cuidado e à prevenção de doenças, adesão ao tratamento e facilidade para o diálogo referente ao diagnóstico. Em relação à postura adotada pelas profissionais há uma contradição, pois ao mesmo tempo em que afirmam não fazer distinções ao atender um homem ou uma mulher, relatam que ao atender o homem é preciso ter um pouco mais de cuidado, mudar a forma de abordar e intervir, e destacam a importância de respeitar a singularidade e a subjetividade de cada um, independente do gênero. A partir das análises desse estudo podemos perceber que as diferenças de gênero são compreendidas pelas psicólogas a partir das experiências diárias da profissão. Essa percepção é ora dada por características físicas, comportamentais e sociais, especialmente influenciadas pela educação e socialização, ora vista com um olhar da sexualidade e ora como uma definição de papéis e atributos impostos pela sociedade. No 
entanto, nos pareceu que no âmbito das práticas está ausente a compreensão da categoria gênero como uma construção histórica de cunho político e social que define e irá ser definida por aquilo que se entende como homem e mulher, como corpo masculino e corpo feminino.

A formação acadêmica foi reconhecida pelas psicólogas como superficial para discutir as questões de gênero e sua relação na prática profissional e com o adoecimento. Cabe destacar que a formação acadêmica promovida atualmente pelas instituições de ensino superior não tem articulado o gênero e a interseccionalidade dentro de suas temáticas de modo a tecer possíveis relações com a saúde física e mental, e também para pensar sobre as ofertas de serviços à população. Embora já reconhecida pelas Ciências Sociais e pela Antropologia, a categoria gênero ainda é pouco abordada nos cursos de Psicologia, sobretudo a partir de uma perspectiva relacional e não pautada puramente no viés biológico ou de desenvolvimento.

Conclui-se que é preciso investir na formação acadêmica desses profissionais, incluindo uma discussão profunda sobre sexualidade, educação sexual e gênero, uma vez que essas questões fazem parte do cotidiano profissional e coadunam com outros fatores para produzir processos de saúde-adoecimento. Apesar de a Psicologia Social ter tido grandes avanços nas áreas referentes à questão de gênero, a formação de modo geral ainda não incorporou a perspectiva do gênero em seus espaços de discussão.

\section{REFERÊNCIAS}

AFONSO, J. de A. Masculino e feminino: alguns aspectos da perspectiva psicanalítica. Scielo.com, 2007.

AQUINO, E. M. L. Saúde do homem: uma nova etapa da medicalização da sexualidade? Ciência \& Saúde Coletiva, Rio de Janeiro, ano 10, n. 1, p. 18-34, 2005.

BANDURA, A. Psychological Modeling: conflicting theories. Chicago: Aldine-Atherton Publ. Co., 1971.

BARBOSA, R. T. de O. Um olhar no tema de homens e masculinidades sobre a saúde do trabalhador. In: SEMINARIO DE SAUDE DO TRABALHADOR DE FRANCA, p. 7, 2010.

BARDIN, L. Análise de conteúdo. Lisboa: Edições 70, 1979.

BENITES, A. P. O.; BARBARINI, N. Histórias de vida de mulheres e saúde da família: algumas reflexões sobre gênero. Scielo, 2009.

BIAGGIO, A. Psicologia do Desenvolvimento. Petrópolis: Vozes, 1976. 
BRAZ, M. A construção da subjetividade masculina e seu impacto sobre a saúde do homem: reflexão bioética sobre justiça distributiva. Ciência \& Saúde Coletiva, Rio de Janeiro, v. 10, n. 1, p. 97-140, 2005.

CAMPOS, L. F. L. Métodos e Técnicas de pesquisa em Psicologia. Campinas, Editora Alínea, 2000.

CECCARELLI, P. R. Diferenças sexuais? Quantas existem? Ceccarelli.psc.br, 1999.

COLOM, R.; ZARO, M. J. Psicologia: das diferenças de sexo. São Paulo, 1. ed., Vetor Editora, 2007.

CONNELL, R. W. Políticas da Masculinidade. Educação e Realidade, v. 20, n. 2, p. 185206, 1995.

COSTA-JUNIOR, F. M. Concepções de médicos/as e enfermeiros/as sobre questões de gênero na saúde. Dissertação (Mestrado em Psicologia do Desenvolvimento e

Aprendizagem), Faculdade de Ciências, Universidade Estadual Paulista, Bauru, 2010.

COSTA-JÚNIOR, F. M.; COUTO, M. T.; MAIA, A. C. B. Gênero e cuidados em saúde: Concepções de profissionais que atuam no contexto ambulatorial e hospitalar. Sexualidad, Salud y Sociedad (Rio de Janeiro), n. 23, p. 97-117, 2016.

COSTA-JUNIOR, F. M.; MAIA, A. C. B. Concepções de homens hospitalizados sobre a relação entre gênero e saúde. Psicologia: Teoria e Pesquisa, v. 25, n. 1, p. 55-63, 2009

COSTA, T.; et al. Naturalization and medicalization of the female body: social control through reproduction. Interface - Comunic., Saúde, Educ., v. 10, n. 20, p. 363-80, jul./dez., 2006.

COURTENAY, W. H. Constructions of masculinity and their influence on men's well-being: a theory of gender and health. Social Science \& Medicine, v. 50, p. 1385-1401, 2000.

COUTO, M. T.; GOMES, R. Homens, saúde e políticas públicas: a equidade de gênero em questão. Ciênc. saúde coletiva, Rio de Janeiro, v. 17, n. 10, out., 2012.

DOYAL, L. Sex, Gender, and health: the need for a new approach. British Medical Journal, v. 323, p. 1061-1063. 2001.

FAGUNDES, A. L. M.; ALMEIDA, A. S.; ANDRADE, D.; MIRANDA, H. Gênero e Psicologia: Um debate em construção no CRP- 03. In: XV Encontro Nacional da Associação Brasileira de Psicologia Social - ABRAPSO, 15, Maceió, Anais ABRAPSO, Maceió: p. 110, 2009.

FERNANDES, L.; CARVALHO, M. C.; Por onde anda o que se oculta: os acessos a mundos sociais de consumidores problemáticos de drogas através do método do snowball. Revista Toxicodependências, v. 6, n. 3, p. 17-28, 2000. 
FERRAZ, D.; KRAICZYK, J. Gênero e Políticas Públicas de Saúde - construindo respostas para o enfrentamento das desigualdades no âmbito do SUS. Revista de Psicologia da UNESP, v. 9, n. 1, p. 70-82, 2017.

FIGUEIREDO, W. Assistência à saúde dos homens: um desafio para os serviços de atenção primária. Ciência \& Saúde Coletiva, Rio de Janeiro, v. 10, n. 1, p. 105-109, 2005.

FIGUEIREDO, W. S. Masculinidades e cuidado: diversidade e necessidades de saúde dos homens na atenção primária. Tese (Doutorado em Medicina Preventiva) - Faculdade de Medicina, Universidade de São Paulo, São Paulo, 2008.

FIGUEIREDO, W. S.; SCHRAIBER, L. B.; Concepções de gênero de homens usuários e profissionais de saúde de serviços de atenção primária e os possíveis impactos na saúde da população masculina; Ciência \& Saúde Coletiva, São Paulo, v. 16, Supl. 1, p. 935-944, 2011.

FOUCAULT, M. Microfísica do Poder. Rio de Janeiro, 3. ed., Graal, 1982

GOMES, R. Sexualidade masculina e saúde do homem: proposta para uma discussão.

Ciência \& Saúde Coletiva, Rio de Janeiro, v. 8, n. 3, p. 825-829, 2003.

GOMES, R. Sexualidade masculina, Gênero e Saúde. Rio de Janeiro: Ed. FIOCRUZ, 2008.

GOMES, R.; NASCIMENTO, E. F.; ARAÚJO, F. C. Por que os homens buscam menos os serviços de saúde do que as mulheres? As explicações de homens com baixa escolaridade e de homens com ensino superior. Cad. de Saúde Pública, Rio de Janeiro, v. 23, n. 3, p. 556-574, 2007.

INSTITUTO DE SAÚDE. Saúde do homem no SUS. São Paulo, v. 14, 2012.

KOFES, S. Categorias analítica e empíricas: gênero e mulher. Ufsc.br, 1992.

KOHLBERG, L. A Cognitive-Developmental Analysis of Children's Sex-role Concepts and Atittudes. In: Maccoby, E. The Development of Sex Differences. Califórnia: Stanford Univ. Press, p. 67-78, 1966.

KORIN, D. Nuevas perspectivas de gênero en salud. Adolescência Latinoamericana, v. 2, n. 2, p. 67-79. 2001.

KRIEGER, N.; FEE, E. Man-made medicine and women's health: the biopolitics of sex/gender and race/ethnicity. International Journalof Health Services, v. 24, n. 2, p. 265283, 1994.

LAMAS, M. O Gênero é cultura? In: V Campus euroamericano de cooperação cultural, Almada, 2007.

MACHADO, I. V.; BARRETO, L. C.; GROSSI, M. P. Processos de ensino e aprendizado de gênero e sexualidades em contexto interdisciplinares. Revista de Ciências Humanas, Florianópolis, v. 47, n. 1, p. 67-80, abr., 2013. Disponível em: 
https://periodicos.ufsc.br/index.php/revistacfh/article/view/2178-4582.2013v47n1p67/26177. Acesso em: 25 ago. 2015.

MACINTYRE, S.; FORD, G. E.; HUNT, K. Do women "over-report" morbidity? Men's and women's responses to structured prompting on a standard question on long standing illness.

Social Science \& Medicine, v. 48, p. 89-98, 1999.

MANZINI, E. J. Entrevista semi-estruturada: análise de objetivos e de roteiros. In: Anais do Seminário internacional sobre pesquisa e estudos qualitativos, 2, 2004, Bauru. A Pesquisa qualitativa em Debate. Bauru: USC, 2004.

MARTIN, V.B.; ANGELO, M. O significado do conceito saúde na perspectiva de famílias em situação de risco pessoal e social. São Paulo, 1996.

MINAYO, M. C. de S. O desafio do conhecimento - pesquisa qualitativa em saúde. 9. ed. São Paulo (SP), Hucitec, 2006.

MIRANDA, D. S.; LOBATO, S. M. R. Processos de adoecimento ligados ao gênero: uma história de (des)valorização dos múltiplos papéis femininos. Belém - PA, 2011.

NEGREIROS, T. C. de G. M.; FERES-CARNEIRO, T.; Masculino e feminino na família contemporânea. Estud. Pesqui. psicol., Rio de Janeiro, v. 4, n. 1, jun., 2004.

NUERNBERG, A. H. Gênero no contexto da produção científica brasileira em psicologia. 2005. 342f. Tese (Doutorado em Ciências Humanas), Universidade Federal de Santa Catarina, Centro de Filosofia e Ciências Humanas, Florianópolis, 2005.

ROHDEN, F. Uma ciência da diferença: sexo e gênero na medicina da mulher. Rio de Janeiro: Editora Fiocruz, 2001.

ROHDEN, F. Ginecologia, gênero e sexualidade na ciência do século XIX. Horiz. Antropol. Porto Alegre, v. 8, n. 17, 2002.

ROHDEN, F. A construção da diferença sexual na medicina. Cad. Saúde Pública, Rio de Janeiro, v. 19, n. 2, p. 201-212, 2003.

ROSA, M. V. F. P. C.; ARNOLDI, M. A. G. C. A entrevista na pesquisa qualitativa: mecanismo para validação dos resultados. Belo Horizonte: Autêntica, 2006.

SCHRAIBER, L. B.; GOMES, R.; COUTO, M. T. Homens e saúde na pauta da saúde coletiva. Ciênc. Saúde Coletiva [online]. 2005.

SCOTT, J. W., Gender and the politics of history, Columbia University Press, New York, 1988.

TEIXEIRA, J. A. C.; CORREIA, A. R. Fragilidade Social e Psicologia da Saúde- Um exemplo de influencias do contexto sobre a saúde. Análise Psicológica, Lisboa, 2002.

VERBRUGGE, L. M. The Twain Meet: Empirical Explanations of Sex Differences in Health and Mortality. Journalof Health and Social Behavior, v. 30, p. 282-304, 1989. 
VIEIRA, E. M.; Medicalização do corpo feminino. Editora Fio Cruz; 2002.

\section{Como referenciar este artigo}

COSTA-JUNIOR, F. M. da.; ALMEIDA, B. dos S.; CORRER, R. Concepções sobre gênero e formação no campo da psicologia da saúde. Revista Ibero-Americana de Estudos em Educação, Araraquara, v. 14, n. esp. 2, p. 1441-1464, jul., 2019. E-ISSN: 1982-5587. DOI: 10.21723/riaee.v14iesp.2.12610

Submetido em: 05/10/2019

Revisões requeridas: 26/10/2019

Aprovado em: 02/02/2019

Publicado em: 26/06/2019 